\title{
Pyrrolo-C as a fluorescent probe for monitoring RNA secondary structure formation
}

\author{
REBECCA A. TINSLEY and NILS G. WALTER \\ Department of Chemistry, University of Michigan, Ann Arbor, Michigan 48109-1055, USA
}

\begin{abstract}
Pyrrolo-C (PC), or 3-[3-D-2-ribofuranosyl]-6-methylpyrrolo[2,3-d]pyrimidin-2(3H)-one, is a fluorescent analog of the nucleoside cytidine that retains its Watson-Crick base-pairing capacity with $\mathrm{G}$. Due to its red-shifted absorbance, it can be selectively excited in the presence of natural nucleosides, making it a potential site-specific probe for RNA structure and dynamics. Similar to 2-aminopurine nucleoside, which base-pairs with uridine (or thymidine), PC's fluorescence becomes reversibly quenched upon base-pairing, most likely due to stacking interactions with neighboring bases. To test its utility as an RNA probe, we examined PC's fluorescent properties over a wide range of ionic strengths, $\mathrm{pH}$, organic cosolvents, and temperatures. Incorporation of PC into a single-stranded RNA results in an $\sim 60 \%$ reduction of fluorescence intensity, while duplex formation reduces the fluorescence by $\sim 75 \%$ relative to the free ribonucleoside. We find that the fluorescence intensity of PC is only moderately affected by ionic strength, $\mathrm{pH}$, and temperature, while it is slightly enhanced by organic cosolvents, making it a versatile probe for a broad range of buffer conditions. We demonstrate two applications for PC: fluorescent measurements of the kinetics of formation and dissociation of an RNA/DNA complex, and fluorescent monitoring of the thermal denaturation of the central segment of an RNA duplex. Taken together, our data showcase the potential of pyrrolo-C as an effective fluorescent probe to study RNA structure, dynamics, and function, complementary to the popular 2-aminopurine ribonucleoside.
\end{abstract}

Keywords: fluorescence anisotropy; fluorescence quenching; melting transition; pyrrolo-cytosine ribonucleoside; RNA folding kinetics

\section{INTRODUCTION}

Fluorescence spectroscopy is a powerful tool for probing the structure and conformational dynamics of biopolymers, as well as their interactions, under a wide range of solution conditions in vitro and in vivo. For example, fluorescence spectroscopy has successfully been utilized to directly observe and quantify conformational change and catalytic function of nucleic acids in solution (Millar 1996; Walter and Burke 2000; Klostermeier and Millar 2001; Walter et al. 2001, 2002; Ha 2004; Zhuang 2005). Unlike proteins, which in many cases carry intrinsic fluorophores such as tryptophan, nucleic acids must be extrinsically labeled, typically with fluorescent organic dyes, due to the low fluorescence quantum yield of their natural components. Even though a plethora of such dyes has been developed (see, e.g., http:// probes.com/), a risk is that they sterically disrupt nucleic acid structure and possibly function. One solution to this problem is the use of fluorescent base analogs as alternative,

Reprint requests to: Nils G. Walter, Department of Chemistry, University of Michigan, Ann Arbor, MI 48109-1055, USA; e-mail: nwalter@ umich.edu; fax: (734) 647-4865.

Article published online ahead of print. Article and publication date are at http://www.rnajournal.org/cgi/doi/10.1261/rna.2165806. less invasive probes of nucleic acid structure, dynamics, and function.

Fluorescent base analogs are valuable in monitoring nucleic acid structural dynamics because they behave similarly to the natural nucleobases in their interactions with other biomolecules (Millar 1996; Jameson and Eccleston 1997; Rist and Marino 2002). They typically do not disrupt duplex formation, making them useful probes of basepairing and base-stacking with neighboring natural bases. Fluorescent base analogs generally have large Stokes shifts and their fluorescence is sensitive to their environment (Jean and Hall 2001), making them good probes of local conformational changes that occur within nucleic acids (Millar 1996; Jameson and Eccleston 1997; Rist and Marino 2002; Walter et al. 2002; Berry et al. 2004). A number of fluorescent base analogs have been incorporated into nucleoside phosphoramidites and thus synthetic nucleic acids. One of the most popular fluorescent nucleobases is 2-aminopurine, an analog of the purines adenine and guanine (Ward et al. 1969; Doudna et al. 1990; Fujimoto et al. 1996; Millar 1996; Rist and Marino 2002). It specifically Watson-Crick base-pairs with thymine or uracil and has proven its utility as a probe to monitor local conformational changes in nucleic acid structure, for example, in 
A

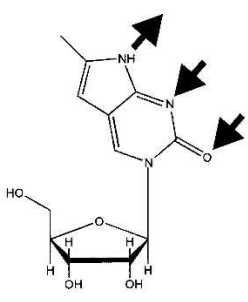

B

SSRNA: 5' AUUCGGUGGGCPCAAUGGACUAU $3^{7}$

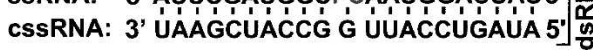

FIGURE 1. Structure of pyrrolo-C (PC) ribonucleoside and incorporation into an RNA. (A) Chemical structure of PC ribonucleoside. (B) RNA oligonuclotides used in this study. The position of PC is highlighted in gray.

catalytic RNA and upon formation of nucleic acid-protein complexes (Millar 1996; O’Neill and Barton 2002; Walter et al. 2002; Patel and Bandwar 2003; Roy 2003; Bradrick and Marino 2004; Clerte and Hall 2004). Several fluorescent pyrimidine analogs also have been developed, although they have not yet reached a similar level of popularity (Inoue et al. 1985; Wu et al. 1990; Godde et al. 1998; Wilhelmsson et al. 2001).

A recent addition to the arsenal of fluorescent pyrimidine analogs available for probing nucleic acids is $3-[\beta-\mathrm{D}-2-$ ribofuranosyl]-6-methylpyrrolo[2,3-d]pyrimidin-2(3H)one, in short pyrrolo-C (PC) (Berry et al. 2004; Fig. 1A). Its 2'-deoxy ribose variant has been successfully used, for example, in the characterization of the transcription bubble in elongation complexes of T7 RNA polymerase (Liu and Martin 2001, 2002), in a biosensor for metal ions (Chen and He 2004), and to characterize local structure in a double-stranded DNA (Johnson et al. 2005) or DNA/ RNA hybrid (Dash et al. 2004). Its unperturbed WatsonCrick face allows PC to base-pair specifically with G, similar to an unmodified cytidine (Fig. 1A). PC is of relatively small size, which is unlikely to perturb the structure of an A-type RNA helix. In addition, it promises to have potent applications in RNA structural analysis as it shares many of the same fluorescence characteristics that make 2-aminopurine ribonucleoside a versatile probe (Berry et al. 2004). PC is highly fluorescent, with excitation and emission maxima of 350 and $460 \mathrm{~nm}$, respectively, relatively far from those of RNA and protein, making it a suitable probe for both RNAs and RNA-protein complexes. Furthermore, the fluorescence of PC is significantly quenched in duplex DNA and RNA, most likely through base-stacking interactions with surrounding nucleotides, rendering it sensitive to its local environment (Liu and Martin 2001, 2002; Berry et al. 2004; Chen and He 2004; Dash et al. 2004).

To explore and evaluate its suitability as fluorescent probe of RNA structure and dynamics, we now have incorporated PC into the middle of a single-stranded RNA
(ssRNA) (Fig. 1B). To study how the fluorescence of PC is affected by duplex formation, we used a complementary strand, termed "cssRNA," to form the corresponding double-stranded RNA complex (dsRNA) (Fig. 1B). We find that the steady-state fluorescence of PC in the single and double strands decreases by $\sim 60 \%$ and $\sim 75 \%$, respectively, relative to the free ribonucleoside. Fluorescence of PC is only moderately affected by ionic strength and $\mathrm{pH}$, while it is slightly enhanced by organic co-solvents, making it a probe suitable for a range of buffer conditions. Exploiting these observations, we demonstrate two applications for PC: (1) We fluorescently measure the kinetics of formation and dissociation of an RNA/DNA hybrid, and (2) we fluorescently monitor the thermal denaturation of the central segment of an RNA duplex and find good agreement with the major, but not a minor lower-temperature, melting transition observed by UV absorbance. Taken together, our data highlight the potential of PC as a fluorescent probe to study RNA structure, dynamics, and function, and suggest it as a suitable experimental counterpart to 2aminopurine ribonucleoside.

\section{RESULTS AND DISCUSSION}

\section{Fluorescence of PC decreases upon RNA duplex formation}

Figure 1 gives the structure and hydrogen-bonding pattern of PC, along with the PC-containing dsRNA used in this study. PC in strand ssRNA is base-paired with guanosine (G) in the fully complementary strand cssRNA. Previous investigations of DNA and DNA/RNA hybrid duplexes by fluorescence spectroscopy suggest that PC undergoes normal Watson-Crick pairing with $\mathrm{G}$ and is well-stacked within the DNA helix in a manner similar to cytosine (Liu and Martin 2001, 2002; Berry et al. 2004; Chen and $\mathrm{He}$ 2004; Dash et al. 2004). To determine the fluorescence characteristics of PC in RNA, we obtained excitation and emission spectra of the ssRNA and its double-stranded form (dsRNA) (Fig. 1) under our standard buffer conditions (chosen to be close-to-physiologic: $50 \mathrm{mM}$ Tris, 25 $\mathrm{mM}$ MES-NaOH, $25 \mathrm{mM}$ acetic acid- $\mathrm{NaOH}$ at $\mathrm{pH}$ 7.5, 100 $\mathrm{mM} \mathrm{NaCl}$ ) at $25^{\circ} \mathrm{C}$. We compared these spectra with those of free PC, obtained by complete degradation of ssRNA with $0.5 \mathrm{U}$ of $\mathrm{S} 1$ nuclease over $1 \mathrm{~h}$ (Fig. 2). Relative to this free PC control, the fluorescence decreases by $\sim 60 \%$ in the intact ssRNA and by $\sim 75 \%$ in the RNA duplex. In addition, the PC excitation and emission maxima are slightly blue-shifted from 353 and $448 \mathrm{~nm}$, respectively, in the free PC control to 352 and $447 \mathrm{~nm}$, respectively, in ssRNA, and to 351 and $443 \mathrm{~nm}$, respectively, in dsRNA (all values obtained by Gaussian fits to the spectra) (Fig. 2). Such a hypsochromic effect is expected for $\pi \rightarrow \pi^{*}$ transitions in the increasingly hydrophobic environment provided by single- and double-stranded base-stacking 
A

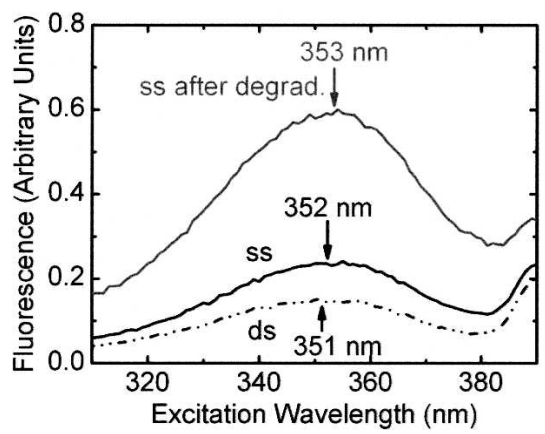

B

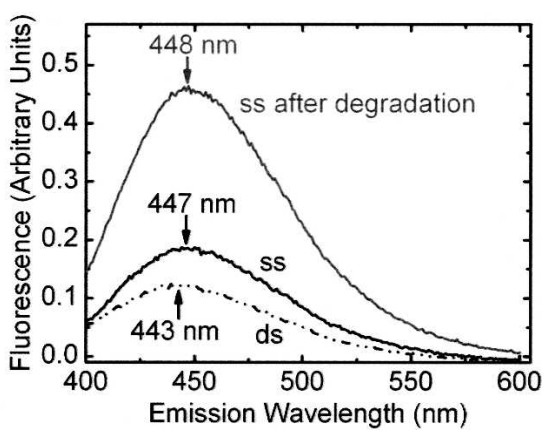

FIGURE 2. Pyrrolo-C fluorescence studies using $1 \mu \mathrm{M}$ ssRNA and $1 \mu \mathrm{M}$ dsRNA in standard buffer (50 mM Tris, $25 \mathrm{mM}$ MES-NaOH, $25 \mathrm{mM}$ acetic acid- $\mathrm{NaOH}$ at $\mathrm{pH} 7.5,100 \mathrm{mM} \mathrm{NaCl}$ ) at $25^{\circ} \mathrm{C}$. Steady-state fluorescence emission $(A)$ and excitation spectra $(B)$ of ssRNA (solid line), dsRNA (dash-dotted line), and ssRNA after complete degradation with $0.5 \mathrm{U}$ of S1 nuclease (gray line), as indicated. The emission and the excitation maxima were obtained as the means of Gaussian fits to the spectra.

(Lakowicz 1999). Similar results were obtained when comparing ssRNA and dsRNA in standard buffer with the directly available free PC as reference; in ssRNA the fluorescence intensity drops to $48 \% \pm 2 \%$, and drops in dsRNA to $31 \% \pm 4 \%$ relative to free PC (Table 1 ).

\section{Fluorescence anisotropy of PC reports on incorporation into RNA and duplex formation}

Fluorescence anisotropy measurements sensitively report on the rotational diffusion of a fluorophore within a biomolecular complex; generally, the higher the anisotropy (or polarization), the less mobile the fluorophore and the larger the complex (Lakowicz 1999). This property should therefore allow us to monitor the incorporation of the small PC into the much larger ssRNA and dsRNA. We find that the free PC has a low anisotropy of 0.06 (Table 1), suggesting that it rotates relatively freely in solution. Upon incorporation into ssRNA, the anisotropy of PC increases by approximately twofold to 0.13 , as expected. Addition of the complementary strand to form dsRNA further increases the anisotropy overall approximately threefold to 0.20 (Table 1). These data suggest that PC becomes increasingly immobile upon incorporation into ssRNA and dsRNA, presumably by a combination of more stable local stacking interactions and slower overall rotational diffusion of the complex.

\section{Monovalent and divalent salts do not significantly affect PC fluorescence}

Monovalent and divalent salts commonly supply the counter-ion charge necessary to promote secondary and tertiary structure folding as the basis for function of a polyanionic RNA in solution (Draper 2004; Woodson 2005). However, it is well known that salts also have the ability to quench fluorophores, for example, by pro- moting the formation of nonfluorescent states (Vamosi et al. 1996). Salts such as $\mathrm{NaCl}, \mathrm{KCl}$, and $\mathrm{MgCl}_{2}$, for example, have been observed to quench the fluorescence of 2-aminopurine and formycin by $15 \%$ (Ward et al. 1969). To evaluate $\mathrm{PC}$ as a probe for RNA folding and function, we therefore examined the effect of salt concentration on its fluorescence. Specifically, we titrated ssRNA and dsRNA, as well as the free PC, with $\mathrm{NaCl}$ and $\mathrm{MgCl}_{2}$ beginning from low-ionic strength buffer conditions $(50 \mathrm{mM}$ Tris, $25 \mathrm{mM}$ MES$\mathrm{NaOH}, 25 \mathrm{mM}$ acetic acid- $\mathrm{NaOH}$ at $\mathrm{pH} 7.5$, containing $\sim 12 \mathrm{mM} \mathrm{Na}^{+}$, at $25^{\circ} \mathrm{C}$ ). Figure $3, \mathrm{~A}$ and $\mathrm{B}$, shows that, upon raising the $\mathrm{MgCl}_{2}$ and $\mathrm{NaCl}$ concentrations by 75 and $100 \mathrm{mM}$, respectively, the normalized fluorescence intensity of ssRNA decreases by $\sim 40 \%$ and $\sim 25 \%$, respectively. In contrast, the normalized fluorescence intensities of both dsRNA and free PC remain virtually constant. These observations suggest that the quenching of fluorescence intensity observed for ssRNA with increasing ionic strength is not an intrinsic property of PC, but is most likely linked to properties of the incorporating ssRNA, for example, enhanced basestacking or secondary structure formation with increasing counter-ion concentration. (To control for the latter, mfold-based structure predictions were performed (Zuker 2003), which generally produced potential secondary structures of low thermodynamic stability [data not shown].) This relatively moderate intrinsic ionic strength dependence recommends PC as a fluorescent probe for a broad set of buffer conditions.

\section{$\mathrm{pH}$ titration of PC fluorescence yields apparent $\mathrm{pK}_{\mathrm{a}} \mathrm{s}$}

Many fluorophores are pH-dependent; however, an important characteristic of a fluorescent probe often is its ability to be used over a wide $\mathrm{pH}$ range. Therefore, we measured the fluorescence intensity of $\mathrm{PC}$ as a function of $\mathrm{pH}$ in the free PC, ssRNA, and dsRNA. Overall,

TABLE 1. Relative fluorescence intensities and anisotropies of free PC, ssRNA, and dsRNA

\begin{tabular}{lrrrr}
\hline & \multicolumn{3}{c}{ Fluorescence intensity } & \\
\cline { 2 - 4 } & \multicolumn{3}{c}{$50 \%$} \\
& Buffer (\%) & \multicolumn{1}{c}{$\begin{array}{c}50 \% \\
\text { ETOH (\%) }\end{array}$} & $\begin{array}{c}\text { Formamide } \\
\text { Anisotropy }\end{array}$ \\
\hline Free PC & $100 \pm 1$ & $353 \pm 1$ & $216 \pm 2$ & $0.06 \pm 0.02$ \\
ssRNA & $48 \pm 2$ & $85 \pm 2$ & $162 \pm 3$ & $0.13 \pm 0.01$ \\
dsRNA & $31 \pm 4$ & $38 \pm 2$ & $98 \pm 1$ & $0.20 \pm 0.02$ \\
\hline
\end{tabular}


A

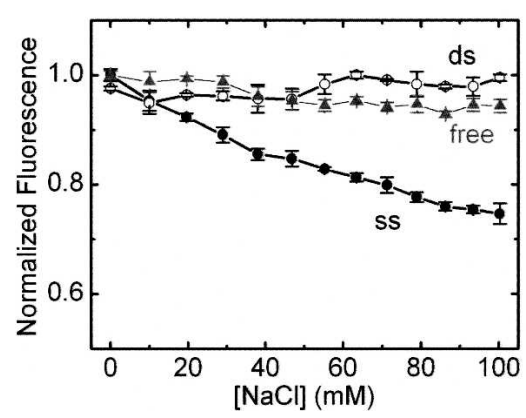

B

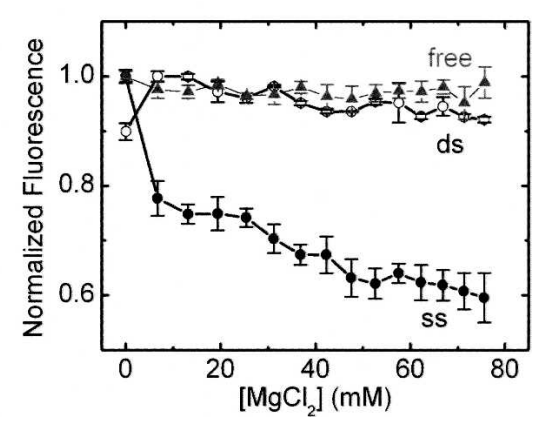

FIGURE 3. Relative fluorescence intensity of free pyrrolo- $\mathrm{C}$ ribonucleoside (gray triangles), ssRNA (filled circles), and dsRNA (open circles) as a function of $\mathrm{NaCl}(A)$ and $\mathrm{MgCl}_{2}(B)$ concentration in $50 \mathrm{mM}$ Tris, $25 \mathrm{mM}$ MES-NaOH , and $25 \mathrm{mM}$ acetic acid- $\mathrm{NaOH}$ (pH 7.5; initially containing $\sim 12 \mathrm{mM} \mathrm{Na}^{+}$) at $25^{\circ} \mathrm{C}$. Errors are derived from at least two independent measurements.

nol or $50 \%$ formamide (normalized to the signal of free PC in buffer). The free PC fluorescence increases 3.5-fold and 2.2-fold upon addition of $50 \%$ ethanol and formamide, respectively. By contrast, the ssRNA fluorescence increases by only twofold upon addition of $50 \%$ ethanol, while the dsRNA signal does not increase significantly. Taken together with our formamide titration data, these results suggest that, first, PC fluorescence is enhanced in a more hydrophobic solvent environment and, second, the presence of RNA secondary structure dampens this enhancement.
$\mathrm{PC}$ fluorescence is $\mathrm{pH}$-independent over a wide range, $\mathrm{pH} 4-9$, and only significantly decreases below $\mathrm{pH} 4$ in all three structural contexts (Fig. 4A). This $\mathrm{pH}$ dependence allowed us to fit the data (see Materials and Methods) to derive apparent $\mathrm{pK}_{\mathrm{a}} \mathrm{s}$ for free PC and PC within ssRNA and dsRNA of 3.3, 2.7, and 3.6 (each \pm 0.3 ), respectively. The $\mathrm{pK}_{\mathrm{a}}$ of $\mathrm{PC}$ therefore appears to be $<4$, slightly lower than cytosine's $\mathrm{pK}_{\mathrm{a}}$ of 4.2 (Saenger 1984). The fact that the three $\mathrm{pK}_{\mathrm{a}} \mathrm{s}$ in different structural contexts are similar suggests that the PC protonation equilibrium is not strongly influenced by stacking or hydrogen bonding interactions.

\section{Organic cosolvents enhance the fluorescence of PC}

Organic cosolvents such as formamide partially denature RNA, which can lead to escape from kinetic folding traps and functional enhancement (Pan and Sosnick 1997; Rook et al. 1998). To investigate the effects of organic cosolvents on PC fluorescence in the context of RNA, we performed a titration of ssRNA, dsRNA, and free PC with up to $50 \%$ formamide in standard buffer at $25^{\circ} \mathrm{C}$. Figure $4 \mathrm{~B}$ shows that in all three cases we observed a monotonous increase in fluorescence intensity by nearly twofold over this range of cosolvent, suggesting a direct effect on the fluorophore rather than the RNA structure.

To further analyze the effect of organic cosolvents on PC fluorescence, we tested the impact of $50 \%$ ethanol. Table 1 gives quantitative PC fluorescence signals for the free PC, ssRNA, and dsRNA in standard buffer with and without a supplement of $50 \%$ etha-

\section{Application example: PC reports on the kinetics of formation and dissociation of an RNA/DNA duplex}

To directly test the utility of PC in a dynamic RNA structure probing application, we designed a steady-state fluorescence assay in which we monitor binding and dissociation of a DNA oligonucleotide termed $\mathrm{cl}$ to ssRNA. $\mathrm{cl}$ is fully complementary to ssRNA and also contains a 10-nt 5'-overhang, which allows its removal by addition of the fully complementary DNA oligonucleotide c2. c2 forms an extended DNA duplex with $\mathrm{cl}$ that displaces ssRNA (Fig. 5A), in analogy to previous conformational shift assays (Yurke et al. 2000; Hoerter et al. 2004). Given that PC fluorescence in double-stranded nucleic acids is quenched, we expect duplex formation of ssRNA with $\mathrm{cl}$ to cause a decrease in PC fluorescence that is reversed upon $\mathrm{c} 2$ addition.

Indeed, upon addition of $1 \mu \mathrm{M} c 1$ to $200 \mathrm{nM}$ ssRNA in standard buffer at $25^{\circ} \mathrm{C}$, we observed an exponential decrease in PC fluorescence over time with a rate constant of $1.93 \mathrm{~min}^{-1}$, indicative of duplex formation (Fig. 5B). After

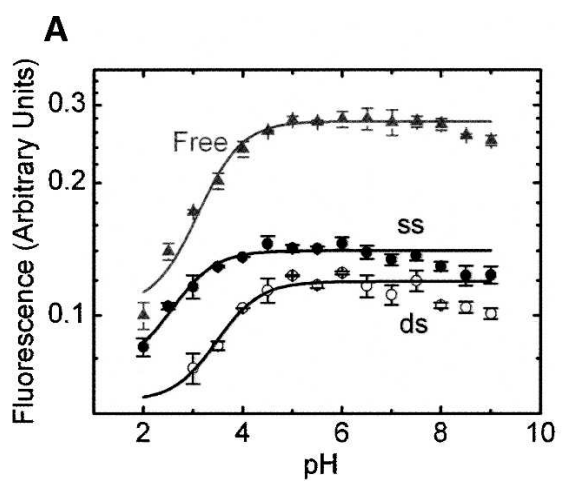

FIGURE 4. The relative fluorescence intensity of free pyrrolo-C ribonucleoside (gray triangles), ssRNA (filled circles), and dsRNA (open circles) as a function of $\mathrm{pH}(A)$ and $(\mathrm{v} / \mathrm{v}) \%$ content $(B)$ of formamide in standard buffer $(50 \mathrm{mM}$ Tris, $25 \mathrm{mM}$ MES-NaOH, $25 \mathrm{mM}$ acetic acid- $\mathrm{NaOH}$ at $\mathrm{pH} 7.5,100 \mathrm{mM} \mathrm{NaCl})$ at $25^{\circ} \mathrm{C}$. Errors are derived from at least two independent measurements.

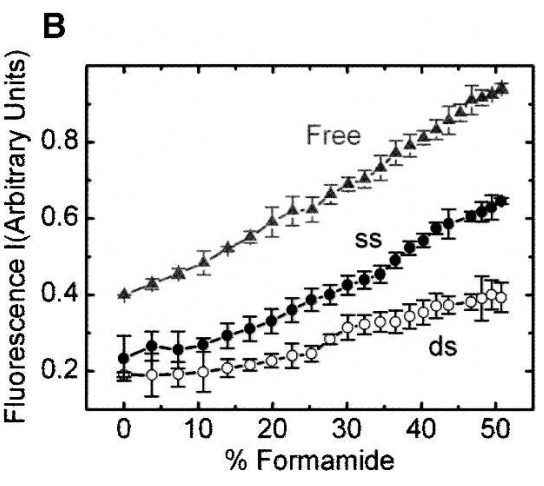

\footnotetext{
(n)

.
} 
A SsRNA

5' AUUCGAUGGCPCAAUGGACUAU:3

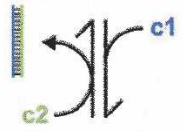

5 ' AUUCGAUGGCPCAAUGGACUAU $3^{*}$

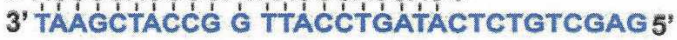
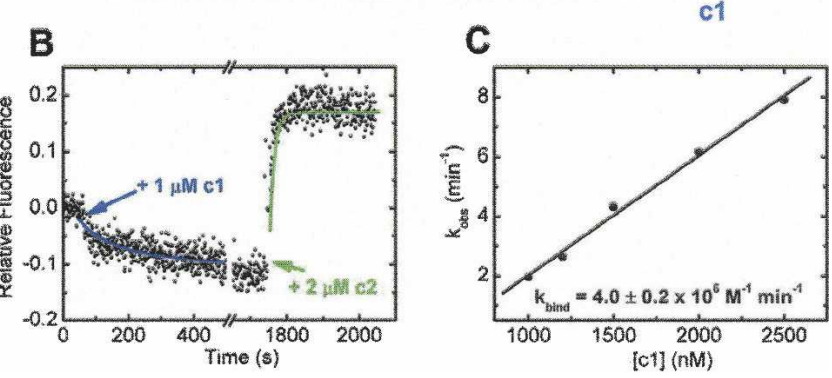

FIGURE 5. Kinetics of formation and dissociation of an RNA/DNA duplex in standard buffer (50 mM Tris, $25 \mathrm{mM}$ MES-NaOH, $25 \mathrm{mM}$ acetic acid- $\mathrm{NaOH}$ at $\mathrm{pH} 7.5,100 \mathrm{mM} \mathrm{NaCl})$ at $25^{\circ} \mathrm{C}$. This assay is analogous to previous conformational shift assays (Yurke et al. 2000; Hoerter et al. 2004) and demonstrates the reversibility of changes in pyrrolo-C fluorescence upon duplex formation. (A) Schematic of the assay. ssRNA binds DNA oligonucleotide c1 (cyan), which is removed by addition of DNA oligonucleotide $\mathrm{c} 2$ (green); gray indicates pyrroloC probe. (B) Upon addition of the DNA oligonucleotide $\mathrm{cl}$ (cyan), the pyrrolo-C fluorescence decreases with a rate of $1.93 \mathrm{~min}^{-1}$. Upon addition of DNA oligonucleotide $\mathrm{c} 2$ (green), the fluorescence decrease is reversed, with a rate of $4.28 \mathrm{~min}^{-1}$. (C) Concentration dependence of the pseudo-first-order rate constant upon addition of excess $\mathrm{cl}$ to ssRNA. The slope of the linear regression line yields the bimolecular rate constant $\mathrm{k}_{\text {bind }}$.

the fluorescence signal equilibrated, we added $2 \mu \mathrm{M} \mathrm{c2,}$ which led to an exponential fluorescence increase at a rate constant of $4.28 \mathrm{~min}^{-1}$, signifying displacement of ssRNA from its hybrid with c1 (Fig. 5B). These results provide direct evidence for PC's capability to monitor in real time the formation and dissociation of a nucleic acid duplex. Furthermore, the pseudo-first-order rate constant of the fluorescence decrease upon $\mathrm{cl}$ addition is linearly dependent on the $\mathrm{cl}$ concentration. From the slope of this dependence, we were able to extract a bimolecular rate constant of $4.0 \pm 0.2 \times 10^{6} \mathrm{M}^{-1} \mathrm{~min}^{-1}$ for ssRNA binding to DNA oligonucleotide $\mathrm{c}$ (Fig. 5C). This rate signifies that binding of $\mathrm{cl}$ is not diffusion limited and is comparable to other bimolecular binding rate constants, such as those of substrate binding to the hairpin and HDV ribozymes (Walter et al. 1997; Harris et al. 2002; Pereira et al. 2002; Jeong et al. 2003).

\section{Application example: PC reports on thermal melting of an RNA duplex}

As a second application example, we sought to demonstrate PC's ability to report on thermodynamic parameters of a dsRNA such as its equilibrium melting. Optical melting curves derived from the hyperchromic shift upon denaturation are frequently used to provide such informa- tion indiscriminately of position in a nucleic acid. By contrast, a site-specifically incorporated fluorescent reporter is expected to monitor nucleic acid melting locally, which can be used to probe specific regions of interest. To demonstrate the validity of using PC to report on local melting in RNA, we obtained first a standard optical melting profile by following the absorption at $260 \mathrm{~nm}$, and second, a melting profile monitored by fluorescence at $347 \mathrm{~nm}$, employing our dsRNA duplex under standard buffer conditions. The equilibrium melting profile monitored by absorption shows two transitions represented by melting temperatures $\left(\mathrm{T}_{\mathrm{m}}\right)$ of $70^{\circ} \mathrm{C}$ and $80^{\circ} \mathrm{C}$ (Fig. $6 \mathrm{~A}$ ).

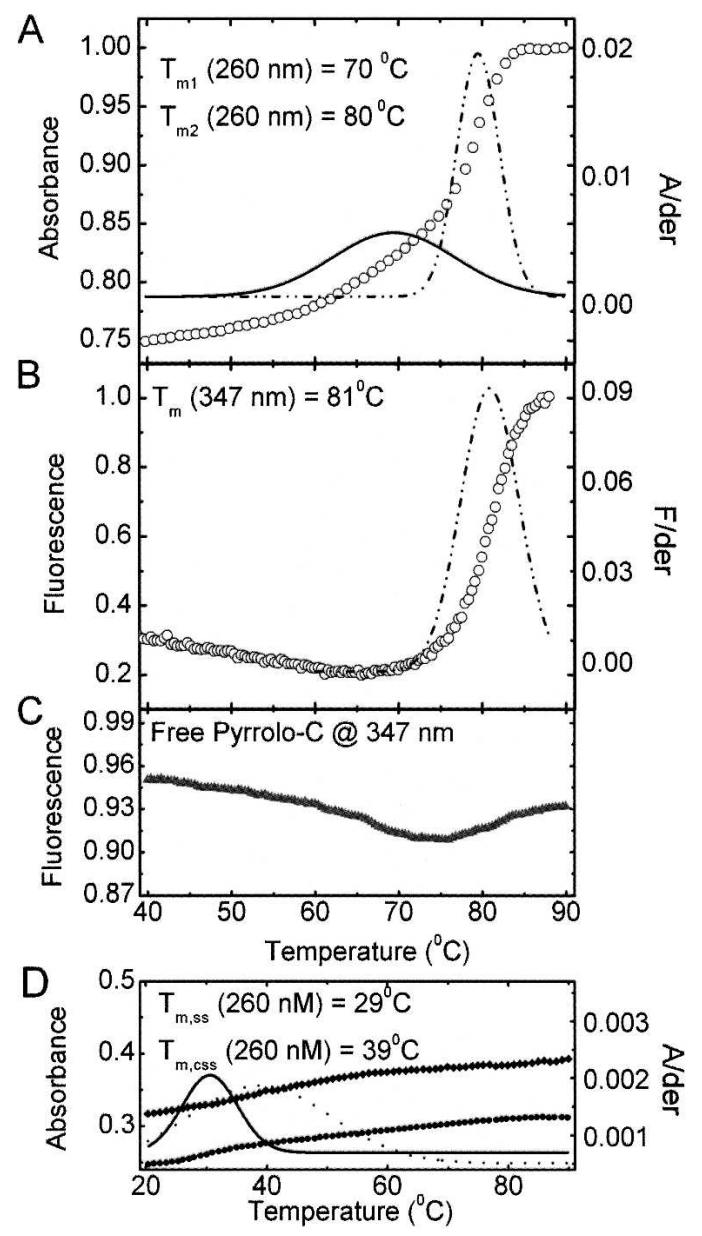

FIGURE 6. Temperature-dependent UV absorbance at $260 \mathrm{~nm}$ and fluorescence emission at $347 \mathrm{~nm}$ of dsRNA. (A) UV melting profile of dsRNA. The relative absorbance of the RNA at $260 \mathrm{~nm}$ (open circles, left axis) and a bimodal Gaussian distribution fit to the smoothed first derivative (solid and dashed/dotted lines, right axis) are shown. Two different melting temperatures $\mathrm{T}_{\mathrm{m} 1}$ and $\mathrm{T}_{\mathrm{m} 2}$ are derived (see Materials and Methods). (B) Fluorescence melting profile of ssRNA (open circles), analyzed as described in $A$. $(C)$ Temperature dependence of the free PC fluorescence (gray triangles). (D) UV melting profile of ssRNA (closed circles) and cssRNA (closed diamonds). The relative absorbance of the RNA at $260 \mathrm{~nm}$ (left axis) and Gaussian distribution fits to the smoothed first derivatives (ssRNA, solid line; cssRNA, dotted line) (right axis) are shown. 
This may represent two different regions of the dsRNA structure melting sequentially. The corresponding melting transition monitored by PC fluorescence at $347 \mathrm{~nm}$ exhibits only a single melting transition at $81^{\circ} \mathrm{C}$, within error $\left( \pm 1^{\circ} \mathrm{C}\right)$ of the major transition in the absorption melting profile (Fig. 6B). Under the same buffer conditions, the fluorescence of the free PC shows only a very slight intrinsic temperature dependence, with a minimum near $\sim 75^{\circ} \mathrm{C}$ (Fig. 6C); this may explain the slight drift in baseline $<70^{\circ} \mathrm{C}$ observed in our fluorescence melting profile (Fig. 6B). As a further control, we obtained optical melting profiles at 260 $\mathrm{nm}$ for ssRNA and cssRNA alone under the same buffer conditions. The profiles each show a very minor transition represented by melting temperatures of $29^{\circ} \mathrm{C}$ and $39^{\circ} \mathrm{C}$, respectively (Fig. 6D), consistent with mfold calculations (Zuker 2003) that predict only potential secondary structures of low thermodynamic stability (data not shown). Therefore, the minor melting transition we observe at $70^{\circ} \mathrm{C}$ in the absorptive melting profile of the ssRNA/ cssRNA duplex cannot be attributed to melting of an excess of one of the two RNA strands. Taken together, our results demonstrate that PC incorporated into the middle of an RNA duplex accurately reports on the main melting transition, independent of minor transitions in the RNA as a whole.

\section{Conclusions}

In summary, we have incorporated the fluorescent cytosine analog 3-[ $\beta$-D-2-ribofuranosyl]-6-methylpyrrolo[2,3d]pyrimidin-2(3H)-one, or PC, into an RNA and shown that it serves as effective probe of kinetic and thermodynamic parameters associated with nucleic acid structure formation. PC is fluorescent over a broad range of solution conditions and becomes reversibly quenched upon basepairing and -stacking in an RNA (or RNA/DNA) duplex. Our results therefore highlight the potential of PC in further applications such as those where the $2^{\prime}$ deoxy modified PC has previously been applied. For example, the local structure in an RNA or RNA/DNA duplex may be probed (Dash et al. 2004; Johnson et al. 2005) or a change in basepairing and/or -stacking upon protein binding be followed (Liu and Martin 2001, 2002; Chen and He 2004). Its relatively small size and full hydrogen bond complementarity to $\mathrm{G}$ promise to make PC a valuable addition to the uridine-paired 2-aminopurine ribonucleoside (Berry et al. 2004).

\section{MATERIALS AND METHODS}

\section{Preparation of RNA oligonucleotides}

PC cyanoethyl phosphoramidite with 2'-O-triisopropylsilyloxymethyl (TOM) protection group and the free ribonucleoside were a gift from Berry and Associates (Dexter, MI). The TOM protected phosphoramidite is now commercially available from Glen Research Corporation; a TBS-protected version is available from Berry and Associates. RNA oligonucleotides (sequences given in Fig. 1) were synthesized commercially by the Howard Hughes Medical Institute Biopolymer/Keck Foundation Biotechnology Resource RNA Laboratory at the Yale University School of Medicine. The RNA contained 2'-protection groups and was deprotected as suggested by the manufacturer by using standard protocols based on triethylamine trihydrofluoride (http://info.med.yale. edu/wmkeck/) (Walter 2001, 2002). Deprotected RNA was purified by denaturing $20 \%$ polyacrylamide and $8 \mathrm{M}$ urea; gel electrophoresis; diffusion elution into $0.5 \mathrm{M} \mathrm{NH}_{4} \mathrm{OAc}, 0.1 \%$ SDS, and $0.1 \mathrm{mM}$ EDTA overnight at $4^{\circ} \mathrm{C}$; chloroform extraction; ethanol precipitation; and $\mathrm{C}_{8}$ reverse-phase HPLC with a linear acetonitrile gradient in triethylammonium acetate as described previously (Walter 2001, 2002). The PC ribonucleoside concentration was calculated from its absorbance at $347 \mathrm{~nm}$ $\left(\varepsilon_{347}=3700 \mathrm{M}^{-1} \mathrm{~cm}^{-1}\right)$, and RNA concentrations were calculated from their absorption at $260 \mathrm{~nm}$.

DNA sequences used in this study were as follows: $\mathrm{c} 1\left(5^{\prime}-G A\right.$ GCTGTCTCATAGTCCATTGGCCATCGAAT-3'), c2 (5'-ATTCGAT GGCCAATGGACTATGAGACAGCTC-3'). Oligodeoxynucleotides were synthesized and desalted by Invitrogen. Synthetic DNA was purified by denaturing $20 \%$ polyacrylamide and $8 \mathrm{M}$ urea, gel electrophoresis, and ethanol precipitation as described above. Stock concentrations were determined from their absorption at $260 \mathrm{~nm}$.

\section{Fluorescence experiments}

All steady-state fluorescence measurements were conducted on an Aminco-Bowman Series 2 (AB2) spectrofluorometer (Thermo Spectronic) using 3-mm path length and $225-\mu \mathrm{L}$ quartz cuvettes. Emission spectra were obtained by exciting at $337 \mathrm{~nm}$ (4-nm bandwidth) and monitoring fluorescence between 400 and 600 $\mathrm{nm}$ (8-nm bandwidth), and excitation spectra were obtained by monitoring fluorescence at $450 \mathrm{~nm}$ (8-nm bandwidth) while scanning excitation wavelengths between 300 and $400 \mathrm{~nm}$ (4-nm bandwidth). Fluorescence anisotropies were measured using the Autopolarizer equipment of the AB2 spectrofluorometer with excitation at $337 \mathrm{~nm}$ (4-nm bandwidth) and emission detection at $450 \mathrm{~nm}$ (8-nm bandwidth). Excitation and emission polarizers were sequentially set to all four possible combinations of vertical $\left(\mathrm{v}, 0^{\circ}\right)$ and horizontal $\left(\mathrm{h}, 90^{\circ}\right)$ alignment-Ivv, Ivh, Ihv, and Ihhto derive the instrument-factor corrected anisotropy A from the expression (Lakowicz 1999):

$$
A=\frac{I_{v v}-g \cdot I_{v h}}{I_{v v}+2 g \cdot I_{v h}}, \text { where } g=\frac{I_{h v}}{I_{h h}}
$$

Experiments were generally carried out at concentrations of 1 $\mu \mathrm{M}$ free PC, ssRNA, and dsRNA in a standard buffer of $50 \mathrm{mM}$ Tris- $\mathrm{HCl}, 25 \mathrm{mM}$ MES-NaOH, and $25 \mathrm{mM}$ acetic acid- $\mathrm{NaOH}$ ( $\mathrm{pH}$ 7.5), $100 \mathrm{mM} \mathrm{NaCl}$, at $25^{\circ} \mathrm{C}$ (to produce dsRNA, ssRNA was annealed with a twofold excess of the complementary strand cssRNA, by heating to $70^{\circ} \mathrm{C}$ for $2 \mathrm{~min}$ and cooling to room temperature over $5 \mathrm{~min}$ ). Nuclease digests were performed by addition of $0.5 \mathrm{U}$ of $\mathrm{S} 1$ nuclease to a fluorescence cuvette with $1 \mu \mathrm{M}$ ssRNA in standard buffer and incubation for $1 \mathrm{~h}$ at $25^{\circ} \mathrm{C}$, at which point the fluorescence signal had stabilized. 
All titrations with the exception of $\mathrm{pH}$ were performed in standard buffer by slowly increasing the amount of titrant. This was accomplished by adding small aliquots of an identical solution but supplemented with $200 \mathrm{mM} \mathrm{MgCl}, 300 \mathrm{mM} \mathrm{NaCl}$, or $75 \%$ formamide, followed by mixing and removal of a solution volume equivalent to that of the added aliquot. This procedure ensures that neither the concentrations of RNA and buffer nor the total solution volume changed over the course of the titration. After each titration step, the solution was equilibrated for 5-10 min until the fluorescence signal had stabilized, and an emission spectrum was recorded as described above. The fluorescence intensity of the peak was extracted by averaging 10 adjacent data points. $\mathrm{pH}$ titrations were performed by preparing a single solution of $1 \mu \mathrm{M}$ RNA or free PC, supplemented with $100 \mathrm{mM} \mathrm{NaCl}$, which was separated into aliquots and buffered to the required $\mathrm{pH}$ using final concentrations of $25 \mathrm{mM}$ sodium citrate (pH 2.0-4.0) or $50 \mathrm{mM}$ Tris, $25 \mathrm{mM}$ MES, and $25 \mathrm{mM}$ acetic acid ( $\mathrm{pH} 4.0-9.0)$. Emission spectra were recorded and analyzed as described above. To derive $\mathrm{pK}_{\mathrm{a}}$ values, the PC fluorescence dependence on $\mathrm{pH}$ was fit with the equation $\mathrm{F}=\mathrm{F}_{0}+\Delta \mathrm{F}_{\max } /\left(1+10^{(\mathrm{pKa}-\mathrm{pH})}\right)$, where $\mathrm{F}_{0}$ is the fluorescence intensity at low $\mathrm{pH}$ and $\Delta \mathrm{F}_{\max }$ is the maximum increase in fluorescence intensity at high $\mathrm{pH}$.

Kinetic binding and dissociation assays were performed by preparing $200 \mathrm{nM}$ ssRNA in standard buffer, which was heated to $70^{\circ} \mathrm{C}$ for $2 \mathrm{~min}$ and cooled to room temperature over $5 \mathrm{~min}$. Oligodeoxynucleotide c1 $(5 \mu \mathrm{L})$ was manually added to a final concentration of $1 \mu \mathrm{M}$. After the fluorescence signal equilibrated, oligodeoxynucleotide c2 $(5 \mu \mathrm{L})$ was added to a final concentration of $2 \mu \mathrm{M}$. The resulting time traces were fit with single-exponential decay and increase functions of the form $y=y_{0}+A\left(e^{-t / \tau}\right)$ and $y=y_{0}+A\left(1-e^{-t / \tau}\right)$, respectively, employing Marquardt-Levenberg nonlinear least-squares regression (Microcal Origin 7.0), where $\mathrm{A}$ is the amplitude and $1 / \tau$ an estimated pseudo-firstorder rate constant. To obtain a binding rate constant for $\mathrm{cl}$, its concentration was varied from 1 to $2.5 \mu \mathrm{M}$, and the resulting concentration dependence was fit by linear regression to yield the bimolecular rate constant $\mathrm{k}_{\mathrm{bind}}$ as the slope.

\section{Thermal denaturation}

Thermal denaturation of $1 \mu \mathrm{M}$ dsRNA at $260 \mathrm{~nm}$ was carried out using a Beckman DU-640B UV-Vis spectrophotometer with High Performance Temperature Controller and Micro Auto $6 \mathrm{~T}_{\mathrm{m}}$ cell holder. RNA samples $(\sim 300 \mu \mathrm{L})$ were prepared as described above in standard buffer, degassed for 5 min prior to obtaining UV melting curves. Absorbance readings at $260 \mathrm{~nm}$ were collected every $1.0^{\circ} \mathrm{C}$ as the sample was heated from $40^{\circ} \mathrm{C}$ to $90^{\circ} \mathrm{C}$ at a rate of $0.2^{\circ} \mathrm{C} / \mathrm{min}$. Melting curves in Figure 6 represent averaged data collected from two melts of freshly prepared dsRNA. After normalization, the first derivative was determined and smoothed by adjacent averaging. The derivative was fit best with two Gaussian distributions using MicroCal Origin 7.0, yielding two melting temperatures.

Thermal denaturation of $1 \mu \mathrm{M}$ dsRNA at $347 \mathrm{~nm}$ was carried out using a Cary Eclipse spectrophotometer (Varian) with a multicell Peltier temperature control. RNA samples $(\sim 1 \mathrm{~mL})$ were prepared as described above in standard buffer and degassed for 5 min prior to obtaining fluorescence melting curves. Fluorescence readings at
$347 \mathrm{~nm}$ were collected every $0.2^{\circ} \mathrm{C}$, as the sample was heated from $40^{\circ} \mathrm{C}$ to $90^{\circ} \mathrm{C}$ at a rate of $0.2^{\circ} \mathrm{C} / \mathrm{min}$. Fluorescence melting curves represent data collected from two melts of freshly prepared dsRNA. After normalization, the first derivative was determined and smoothed by adjacent averaging. The derivative was best fit with a single Gaussian function using MicroCal Origin 7.0.

\section{ACKNOWLEDGMENTS}

We thank Will Pearson and Berry and Associates for supplying the PC phosphoramidite before it became commercially available. We also thank Carol Fierke for use of her Cary Eclipse spectrophotometer. This work was supported in part by NIH grant GM62357 (N.G.W.) and supplement GM62357-S1 (R.A.T.).

Received July 20, 2005; accepted November 19, 2005.

\section{REFERENCES}

Berry, D.A., Jung, K.Y., Wise, D.S., Sercel, A.D., Pearson, W.H., Mackie, H., Randolph, J.B., and Somers, R.L. 2004. Pyrrolo-dC and pyrrolo-C: Fluorescent analogs of cytidine and 2'-deoxycytidine for the study of oligonucleotides. Tetrahedron Lett. 45: 24572461.

Bradrick, T.D. and Marino, J.P. 2004. Ligand-induced changes in 2aminopurine fluorescence as a probe for small molecule binding to HIV-1 TAR RNA. RNA 10: 1459-1468.

Chen, P. and He, C. 2004. A general strategy to convert the MerR family proteins into highly sensitive and selective fluorescent biosensors for metal ions. J. Am. Chem. Soc. 126: 728-729.

Clerte, C. and Hall, K.B. 2004. Global and local dynamics of the U1A polyadenylation inhibition element (PIE) RNA and PIE RNA-U1A complexes. Biochemistry 43: 13404-13415.

Dash, C., Rausch, J.W., and Le Grice, S.F. 2004. Using pyrrolo-deoxycytosine to probe RNA/DNA hybrids containing the human immunodeficiency virus type-1 $3^{\prime}$ polypurine tract. Nucleic Acids Res. 32: 1539-1547.

Doudna, J.A., Szostak, J.W., Rich, A., and Usman, N. 1990. Chemical synthesis of oligoribonucleotides containing 2-aminopurine: Substrates for the investigation of ribozyme function. J. Org. Chem. 55: 5547-5549.

Draper, D.E. 2004. A guide to ions and RNA structure. RNA 10: 335343.

Fujimoto, J., Nuesca, Z., Mazurek, M., and Sowers, L.C. 1996. Synthesis and hydrolysis of oligodeoxyribonucleotides containing 2aminopurine. Nucleic Acids Res. 24: 754-759.

Godde, F., Toulme, J.J., and Moreau, S. 1998. Benzoquinazoline derivatives as substitutes for thymine in nucleic acid complexes: Use of fluorescence emission of benzo[g]quinazoline-2,4-(1H,3H)-dione in probing duplex and triplex formation. Biochemistry 37: 1376513775.

Ha, T. 2004. Structural dynamics and processing of nucleic acids revealed by single-molecule spectroscopy. Biochemistry 43: 40554063.

Harris, D.A., Rueda, D., and Walter, N.G. 2002. Local conformational changes in the catalytic core of the trans-acting hepatitis delta virus ribozyme accompany catalysis. Biochemistry 41: 12051-12061.

Hoerter, J.A., Lambert, M.N., Pereira, M.J., and Walter, N.G. 2004 Dynamics inherent in helix 27 from Escherichia coli $16 \mathrm{~S}$ ribosomal RNA. Biochemistry 43: 14624-14636.

Inoue, H., Imura, A., and Ohtsuka, E. 1985. Synthesis and hybridization of dodecadeoxyribonucleotides containing a fluorescent pyridopyrimidine deoxynucleoside. Nucleic Acids Res. 13: 7119-7128.

Jameson, D.M. and Eccleston, J.F. 1997. Fluorescent nucleotide analogs: Synthesis and applications. Methods Enzymol. 278: 363-390. 
Jean, J.M. and Hall, K.B. 2001. 2-Aminopurine fluorescence quenching and lifetimes: Role of base stacking. Proc. Natl. Acad. Sci. 98: $37-41$.

Jeong, S., Sefcikova, J., Tinsley, R.A., Rueda, D., and Walter, N.G. 2003. Trans-acting hepatitis delta virus ribozyme: Catalytic core and global structure are dependent on the $5^{\prime}$ substrate sequence. Biochemistry 42: 7727-7740.

Johnson, N.P., Baase, W.A., and von Hippel, P.H. 2005. Investigating local conformations of double-stranded DNA by low-energy circular dichroism of pyrrolo-cytosine. Proc. Natl. Acad. Sci. 102: 7169-7173.

Klostermeier, D. and Millar, D.P. 2001. RNA conformation and folding studied with fluorescence resonance energy transfer. Methods 23: $240-254$.

Lakowicz, J.R. 1999. Principles of fluorescence spectroscopy, 2d ed. Springer Publishers, Dordrecht, Netherlands.

Liu, C. and Martin, C.T. 2001. Fluorescence characterization of the transcription bubble in elongation complexes of T7 RNA polymerase. J. Mol. Biol. 308: 465-475.

. 2002. Promoter clearance by T7 RNA polymerase: Initial bubble collapse and transcript dissociation monitored by base analog fluorescence. J. Biol. Chem. 277: 2725-2731.

Millar, D.P. 1996. Fluorescence studies of DNA and RNA structure and dynamics. Curr. Opin. Struct. Biol. 6: 322-326.

O'Neill, M.A. and Barton, J.K. 2002. 2-Aminopurine: A probe of structural dynamics and charge transfer in DNA and DNA:RNA hybrids. J. Am. Chem. Soc. 124: 13053-13066.

Pan, T. and Sosnick, T.R. 1997. Intermediates and kinetic traps in the folding of a large ribozyme revealed by circular dichroism and UV absorbance spectroscopies and catalytic activity. Nat. Struct. Biol. 4: 931-938.

Patel, S.S. and Bandwar, R.P. 2003. Fluorescence methods for studying the kinetics and thermodynamics of transcription initiation. Methods Enzymol. 370: 668-686.

Pereira, M.J., Harris, D.A., Rueda, D., and Walter, N.G. 2002. Reaction pathway of the trans-acting hepatitis delta virus ribozyme: A conformational change accompanies catalysis. Biochemistry 41: 730-740.

Rist, M.J. and Marino, J.P. 2002. Fluorescent nucleotide base analogs as probes of nucleic acid structure, dynamics and interactions. Curr. Org. Chem. 6: 775-793.

Rook, M.S., Treiber, D.K., and Williamson, J.R. 1998. Fast folding mutants of the Tetrahymena group I ribozyme reveal a rugged folding energy landscape. J. Mol. Biol. 281: 609-620.

Roy, S. 2003. On the use of 2-aminopurine as a probe for base pair opening during transcription initiation. Methods Enzymol. 370: $568-576$.
Saenger, W. 1984. Principles of nucleic acid structure. Springer-Verlag, New York.

Vamosi, G., Gohlke, C., and Clegg, R.M. 1996. Fluorescence characteristics of 5-carboxytetramethylrhodamine linked covalently to the $5^{\prime}$ end of oligonucleotides: Multiple conformers of singlestranded and double-stranded dye-DNA complexes. Biophys. J. 71: 972-994.

Walter, N.G. 2001. Structural dynamics of catalytic RNA highlighted by fluorescence resonance energy transfer. Methods 25: 19-30.

. 2002. Probing RNA structural dynamics and function by fluorescence resonance energy transfer (FRET). Curr. Protocols Nucleic Acid Chem. 11.10: 11.10.11-11.10.23.

Walter, N.G. and Burke, J.M. 1997. Real-time monitoring of hairpin ribozyme kinetics through base-specific quenching of fluoresceinlabeled substrates. RNA 3: 392-404.

. 2000. Fluorescence assays to study structure, dynamics, and function of RNA and RNA-ligand complexes. Methods Enzymol. 317: 409-440.

Walter, N.G., Chan, P.A., Hampel, K.J., Millar, D.P., and Burke, J.M. 2001. A base change in the catalytic core of the hairpin ribozyme perturbs function but not domain docking. Biochemistry 40: 25802587.

Walter, N.G., Harris, D.A., Pereira, M.J., and Rueda, D. 2002. In the fluorescent spotlight: Global and local conformational changes of small catalytic RNAs. Biopolymers 61: 224-242.

Ward, D.C., Reich, E., and Stryer, L. 1969. Fluorescence studies of nucleotides and polynucleotides, I: Formycin, 2- aminopurine riboside, 2,6-diaminopurine riboside, and their derivatives. J. Biol. Chem. 244: 1228-1237.

Wilhelmsson, L.M., Holmen, A., Lincoln, P., Nielsen, P.E., and Norden, B. 2001. A highly fluorescent DNA base analogue that forms Watson-Crick base pairs with guanine. J. Am. Chem. Soc. 123: 2434-2435.

Woodson, S.A. 2005. Metal ions and RNA folding: A highly charged topic with a dynamic future. Curr. Opin. Chem. Biol. 9: 104-109.

Wu, P.G., Nordlund, T.M., Gildea, B., and McLaughlin, L.W. 1990. Base stacking and unstacking as determined from a DNA decamer containing a fluorescent base. Biochemistry 29: 6508-6514.

Yurke, B., Turberfield, A.J., Mills Jr., A.P., Simmel, F.C., and Neumann, J.L. 2000. A DNA-fuelled molecular machine made of DNA. Nature 406: 605-608.

Zhuang, X. 2005. Single-molecule RNA science. Annu. Rev. Biophys. Biomol. Struct. 34: 399-414.

Zuker, M. 2003. Mfold web server for nucleic acid folding and hybridization prediction. Nucleic Acids Res. 31: 3406-3415. 

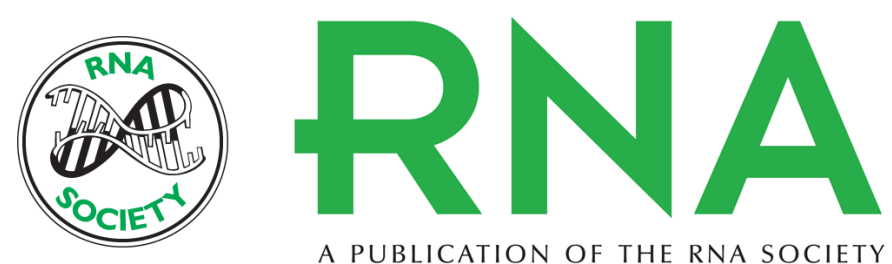

A PUBLICATION OF THE RNA SOCIETY

\section{Pyrrolo-C as a fluorescent probe for monitoring RNA secondary structure formation}

REBECCA A. TINSLEY and NILS G. WALTER

RNA 2006 12: 522-529

References This article cites 42 articles, 7 of which can be accessed free at:

http://rnajournal.cshlp.org/content/12/3/522.full.html\#ref-list-1

\section{License}

Email Alerting Receive free email alerts when new articles cite this article - sign up in the box at the Service top right corner of the article or click here.

To subscribe to RNA go to:

http://rnajournal.cshlp.org/subscriptions 